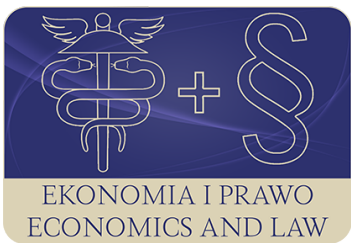

EKONOMIA I PRAWO. ECONOMICS AND LAW

Volume 19, Issue 1, March 2020

p-ISSN 1898-2255, e-ISSN 2392-1625

www.economicsandlaw.pl

BOOK REVIEW

received 18.01.2020; revised 24.01.2020; accepted 31.03.2020

Citation: Osińska, M. (2020). Book review: Gorynia, M. (Ed.). (2019). Ewolucja nauk ekonomicznych: jedność a różnorodność, relacje do innych nauk, problemy klasyfikacyjne. Ekonomia i Prawo. Economics and Law, 19(1): 201-210. doi:10.12775/EiP.2020.014.

\title{
Book review: Gorynia, M. (Ed.). (2019). Ewolucja nauk ekonomicznych: jedność a różnorodność, relacje do innych nauk, problemy klasyfikacyjne
}

Warszawa: Polska Akademia Nauk. ISBN 978-83-63305-66-6. pp. 253.

\section{MAGDALENA OSIŃSKA}

\author{
Nicolaus Copernicus University in Toruń, Faculty of Economic Sciences and Management, \\ Department of Economics, ul. Gagarina 13 A, 87-100 Toruń, Poland \\ 曰emo@umk.pl \\ (D) orcid.org/0000-0002-9796-2892
}

\section{Introduction}

The debate on the evolution of economic sciences has become extremely important in the era of globalization, technological development and deep social changes. A particularly influential debate was held in the Massachussets Institute of Technology in 2011. Daron Acemoglu, Peter Diamond, Esther Duflo, Robert Hall and Robert M. Solow discussed the historical perspective of macroeconomics and its microeconomic foundations, development economics, labour market, and economic policy based on the scientific foundations. It is hard to imagine now what R. Solow meant when he took his first economics course in 1940, 'there was no such a thing as macroeconomics' (ODL Video Services, 2018).

From a contemporary perspective one can notice that the development of economic sciences was very fast though it happened in an evolutionary way. Topics, which were considered to be marginal at the beginning, are gaining 
more attention by extending research interests, new findings and finally creating a stream of ideas, which becomes an inextricable part of economics. The examples include new institutional economics, evolutionary economics, experimental economics, behavioural economics, and also financial econometrics - a subdiscipline being a response to the need of the analysis of specific characteristics of financial processes.

In Poland, the debate on economic sciences and their evolution was initially undertaken by researchers connected with the Committee on Economic Sciences of the Polish Academy of Sciences ${ }^{1}$ and the Scientific Council of the Polish Economic Society. The debate was commenced in 2013 and it is still continued today. Its results have been collected and presented in a monograph entitled The evolution of economic sciences: unity and diversity, relations to other sciences, classification problems edited, co-authored and coordinated by Marian Gorynia. The monograph was published to sum up a set of conferences, presentations and reflections that took place in the years 2013 and 2018. The direct impulse to prepare the book was the conference organized in March 2018 in Warsaw.

To let speak the arguments specific to different subdisciplines recognized within economic sciences, the authors who participated in the debate represented various scientific committees: the Committee on Economic Sciences, the Committee on Demographic Studies, the Committee on Financial Sciences, the Committee on Labour and Social Policy Sciences, the Committee on Organizational and Management Sciences and the Committee on Statistics and Econometrics (Polish Academy of Sciences, 2020).

\section{The body of the publication}

The objective of the monograph is to present how the distinctness and similarity of one discipline (or one subdiscipline) is manifested in relations to others. The issues discussed in the monograph are divided into three parts, each composed of four chapters, while the introduction and the first chapter are general and they are not connected to any other part.

The first chapter authorized by M. Gorynia is entitled Contemporary economic sciences: identity, evolution, classifications. M. Gorynia formulated four goals of the analysis: establishing the basic dimensions of the identity of economic sciences; identifying the manifestations of diversity and regularity on 'the market' of paradigms in economic sciences; discussing the manifestations and possible consequences of interdisciplinarity related to economic sciences, and reflecting on the future of economic sciences. In the conclusions section, he formulated ten recommendations for further research to be undertaken in economic sciences. The author identifies that the general goal of economics has not been changed and is related to the effectiveness of using rare resources having con-

${ }^{1}$ Scientific Committees - bodies representing the research community in specific scientific disciplines, integrating researchers across Poland (Polish Academy of Sciences, 2020). 
trolled individual and social effects of economic activity. He finds that main disciplines classified into the economic sciences answer to the needs of this general goal and that it is still present in contemporary research. M. Gorynia represents the viewpoint that diversity of theories related to the main goal of the research is what is both natural and desired in the evolution of economic sciences. Additionally, greater openness to interdisciplinarity of economic sciences understood in two dimensions (i.e., formal and actual) is recommended.

The first part of the book is an overview of the viewpoints represented by two research committees, i.e., the Committee on Economic Sciences and the Committee on Financial Sciences. It consists of four chapters.

The chapter on Distinction of orthodoxy and heterodoxy in light of the need for methodological pluralism in economics: microeconomic perspective was written by Bogusław Fiedor. The author starts with a thesis stating that "there is taking place a growing methodological and epistemological diversification within the economics as a science, particularly in view of two kinds of dualism: economics as a nomological science versus applied science, and, secondly, the distinction between a descriptive (positive) and normative stream'. Furthermore, he lays emphasis on the necessity of increasing methodological pluralism of economic sciences, particularly when opting for the rejection of mainstream model-deductive formalism and allowing the historical-descriptive analysis as equally legitimate in economics. Based on the wide literature study, he defines orthodoxy vs. heterodoxy in the context of economic pluralism. It was stated that even in the mainstream economics based on the neoclassical paradigm, there are plenty of internally distinctive ideas, similarly heterogeneity is what characterizes new institutional economics or complexity economics. The chapter gives a complex and composed review of economic ideas, paradigms and methods placing behavioural origin of the decision-making process in the centre of deliberations in microeconomics.

Jerzy Wilkin authored the chapter entitled Science in breaking any borders, also in economics. He argues that 'progress in science, including economics, depends significantly on conditions determined inside particular science and outside, especially in institutional conditions or socio-economic systemic environment'. Particularly, the focus is on barriers and consequences of divisions, classifications and limitations present in the scientific sector in Poland as well as their mainly negative consequences for the process of openness and development research in different areas of economics.

The phenomenon of economic crisis is what attracted the general attention to the state of arts of economic sciences. Andrzej Wojtyna raises this issue in the consecutive chapter: Research in economics responding to the recent world crisis: permanent or transitory changes? He posed a question whether 'changes in the way of conducting research (a methodological aspect) should be separated from changes in its explanatory power'. Understanding a complementary character of these two parts, the author indicates that rigorous methodological requirements may lead to incomplete understanding of real-world economic 
processes. A. Wojtyna singles out three permanent changes in economics in reaction to the recent world crisis, i.e., 'more emphasis on interactions between economic and financial factors; increasing openness of the mainstream to behavioural economics' and 'a much bigger significance attached to income and wealth distribution and its role in economic growth and development'.

A financial perspective on the state of arts of contemporary research is the subject of the sequent chapter authored by Stanisław Flejterski. The paper entitled The contemporary sciences of finances: the methodological status, structure, environment, paradigms attempts to show the methodological status of the science of finance, the specifics and the paradigms of the discipline, and presents its position in the system of contemporary economic sciences. He stated that finance is a highly complex discipline, with many classical and new subdisciplines, having strong relations with numerous economic and non-economic disciplines. He postulated 'the desired methodological approaches in finance in the twenty-first century'. These are the interdisciplinary approach represented by complexity theory, comparative analysis, long-term thinking, empirical research, quantitative approach, experimental finance, and ethics in finance, ecology in finance, digital finance, heterodoxy, and sustainable finance.

Part II of the publication consists of reflections presented by the members of the Committee on Organizational and Management Sciences and the Committee on Statistics and Econometrics.

In the opening chapter The concept of management, scope and limits of management sciences, their place in the classification of sciences and sub-disciplines Stanisław Sudot claims that there is no uniform understanding of the concept of management in Poland and in the world. He recognizes management is a very complex process and locates management sciences within practical social sciences. He also refers to the presence of management sciences in two areas of classification, i.e., in economic sciences and in the humanities which is no longer valid. The claim that 'management sciences should not be understood as interdisciplinary' refers directly to the past classification and may be misleading in the context of the scope of interest as well as the relations with other disciplines. S. Sudot fights for integrity of management sciences in the presence of the diversity of topics of interest.

The management science viewpoint is also represented by Wojciech Czakon, the author of the chapter Management research identity: development, legitimation, key features. He emphasizes 'action, not truth as the central management epistemological category'. W. Czakon points to institutions as important elements of the evolution of management sciences. He finds that institutional development of this discipline, which can be observed across study programmes, scientific and professional associations, as well as system of accreditations, is both intentional and reactive, and it is a response to the economic and social needs as well as the needs for research to solve diagnosed problems. The subject of analysis in management sciences is then cooperation of people who care for 
management efficiency in the organization. Furthermore, all methods available for research are allowed.

Mirostaw Szreder emphasizes the challenges coming from big data for statistics in his chapter: The role of statistical surveys in economics in the light of new opportunities provided by big data. His paper discusses some major trends in the development of statistical surveys and in their applications in economics as well as the consequences of the technological revolution which facilitates access to various data sources, and creates new opportunities for collecting, processing and analysing data. He considers big databases to be an opportunity for economic research.

The next chapter is Economic sciences: dilemmas of the classification of disciplines: tendencies of changes. Apart from the discussion on the classification of disciplines within economic sciences, its author - Krzysztof Jajuga indicates the most important determinants that influence and will continue to influence the development of economic sciences. The following tendencies are mentioned: over-formalization without the right economic perspective, data exploration and growing interdisciplinarity. He distinguishes the following three determinants of changes: technological, social, and institutional and discusses their consequences for economics students teaching.

The researchers representing the Committee on Demographic Studies and the Committee on Labour and Social Policy Sciences prepared their chapters that are contained in the third part of the monograph. Part III also consists of four chapters.

Irena E. Kotowska authored the chapter opening the third part entitled On evolving population research and interrelationships between demography and economics: an outline. She presented a comprehensive evolution in population processes studies with reference to research on changes in population reproduction carried out in European countries. She emphasizes that research needs, including research in economics, are strictly related to the transformation of population reproduction and its diverse course across countries and continents. The main challenges in the demographic studies are centred on developments in analytical methods, progressing in empirical studies and data bases and strengthening interlinks with other scientific disciplines.

Elżbieta Gołata and Maciej Beręsewicz wrote a chapter entitled The future of statistical research on social and economic needs based on the example of censuses. The chapter is particularly important when one realizes that a census is an illustration of the oldest way of collecting statistical data. Nowadays, censuses are still an essential part of the national and international official statistics system. The authors analyse organizational changes in statistical surveys, methods of conducting and transforming censuses, threats and prospects related to the use of non-statistical data sources as alternative methods of carrying out a census.

Marta Juchnowicz is the author of the following chapter: Development of human resources management: towards human capital. Its aim is to 'indicate core 
assumptions of modernizing the personnel function performance within organizations and to present major concepts of human resource management, as a response to these challenges'. She mentions the following challenges of human resource management: technological changes, mainly of digital nature, the demographic processes and features of new models of organizational structures.

A comprehensive study reporting development of labour economics is presented by Eugeniusz Kwiatkowski in the chapter entitled Directions and nature of research in labour economics and its relations to scientific disciplines. He studied labour economics from its genesis through development as well as relations between labour economics and other sciences. The author emphasizes the contribution to the formation of modern labour economics made by the new institutional economics 'in which the synthesis was made between institutional approach and main ideas of the mainstream of economics'. Furthermore, he finds the usefulness of formal quantitative approaches for the analyses of the labour market. The latter could help the labour economics to enter the mainstream of economic sciences. The chapter focuses on the contribution of the international research to the evolution of labour economics as a subdiscipline.

\section{Comments, remarks and recommendations}

The monograph The evolution of economic sciences: unity and diversity, relations to other sciences, classification problems edited by M. Gorynia presents a set of consistent and comprehensive studies on the objectives, ideas, genesis, evolution and challenges of economic sciences. The publication provides an up-to-date and important input into the global debate on the way of evolution of economic sciences. The formal classifications on both international and domestic levels are included into the debate to show mutual relations between the disciplines as well as the limitations for different areas and methods.

The general conclusion is that the modern shape of many economic disciplines has been created since the 1940s, when new formal and informal institutions and processes appeared and developed. However, the pioneering theories are often still present or they evolved over time giving the right background for solving contemporary problems.

The advantages of the publication can be indicated explicitly:

- it refers to both general and specific viewpoints; not only perspectives of different disciplines are present but also trends in the economic sciences observed globally are discussed within the context of the current state of arts in Poland;

- it presents a wide survey of research problems that are the subject of interest in different disciplines and subdisciplines;

- it exhibits openness to heterodox economic ideas;

- it is inclusive into global development of economic thought;

- it has been written by specialists in a competent manner but the language is not hermetic, thus can be used in both scientific and popular debates; 
- it is logically structured and shows the relations between different disciplines and subdisciplines belonging to economic sciences;

- it contains the author index and the topic index as well as biographical notes of the authors.

The book should be recommended and widely distributed across a wide audience, including researchers, $\mathrm{PhD}$ and MA students of economics, finance and management, as well as all persons interested in the structure of economic sciences and their interrelations and contemporary challenges.

From my personal perspective, there are some minor comments that might be taken into account when reading. Firstly, the intention of international recognition of the viewpoints expressed in the debate held in Poland should be assumed. Thus, it would be very useful if a brief description of the book was prepared in English. Although English versions of the abstracts of particular chapters are published, the general overview seems to be missing for an international reader. Secondly, the structure of the book is a bit too formal from the general perspective, since the chapters are presented not according to the defined problems but their sequence takes into account the presence of the Committees of the Polish Academy of Sciences. Such logic is visible and acceptable, however, some parts could be considered jointly by themes. Thirdly, looking at the applicability of the statistical and econometric methods across different disciplines of economic sciences, it would be useful to complete them by topics. It was partially presented by K. Jajuga, while mentioning Nobel Memorial Prizes in Economic Sciences. For example, macroeconomics developed much thanks to the idea of econometric macromodelling and simulating possible scenarios, also from a concept of cointegration, a vector autoregression model and, so popular recently, panel data models. The microeconomic issues related to the consumer behaviour and labour market analysis contributed from microeconometric tools, such as logit models, panel data models and simulation techniques. The contribution of portfolio analysis as well as volatility models into financial risk analysis are not to be overestimated. Finally, management sciences use Structural Equation Models and optimization-based models in the decision process assessment. This non-exhaustive set of examples shows that the socalled quantitative methods have been included into development of economic sciences. These examples are not in contradiction with the viewpoints, represented by some authors of the reported monograph, that a balance between application of quantitative methods and possibility of their interpretation as well as historical and descriptive perspectives is necessary. As everywhere, proper tools should be designed to solve specified economic problems.

I started the analysis with mentioning the debate that took place in the USA in 2011. The eight-year gap between that debate and editing the reported monograph did not change much in the perspective of the challenges facing economic sciences. Going back to the debate held at the MIT, it is worth noting that the speakers concentrated on the problems which kept the development of economics in motion and discussed currently important issues in the US economy 
and globally. These problems are as follows: the evolution of macroeconomics in the past century and the emergence of microeconomic foundations in macroeconomics, the application of economic analysis to such issues as structural unemployment, the ongoing U.S. recession, and the best ways to help developing nations. The publication edited by M. Gorynia completes the viewpoints presented by the American researchers by both discussing general problems in the chapters authored by M. Gorynia, B. Fiedor, A. Wojtyna and E. Kwiatkowski, but also by analysing specific problems, such as big data in statistics, population processes or methodology of census. The other chapters are more concentrated on problems of classification of economic sciences (including specifically Polish situation) and the identity of management sciences, which were not analysed in the USA.

Re-assuming the above arguments, it seems nowadays that the new classification of the disciplines introduced in Poland in 2018 is - in the area of economic sciences - clear, and it distinctly shows the differences between them. Nevertheless, any classification is biased towards its criterion and cannot be thought as universal in the long run. As the debate showed, the development of important and fascinating topics, areas, issues, methods, tools and disciplines is much more complicated than any attempt at classifying them. Let economic sciences develop in an evolutionary way!

\section{References}

Polish Academy of Sciences. (2020). Retrieved 17.01.2020 from https://institution.pan.pl.

ODL Video Services. (2018). The evolution of economic science: macroeconomics, growth, and development. Retrieved 09.01.2020 from https://techtv.mit.edu.

\section{Notes}

Author contributions: author has given an approval to the final version of the article. 